\title{
Evaluation of hyperacute infarct volume using ASPECTS and brain CT perfusion core volume OPEN
}

Jelle Demeestere, MD* Carlos Garcia-Esperon, MD*

Pablo Garcia-Bermejo, MD

Fouke Ombelet, BN Patrick McElduff, PhD Andrew Bivard, PhD Mark Parsons, MD, PhD Christopher Levi, MD

Correspondence to Dr. Levi:

Christopher.levi@hnehealth.nsw. gov.au

Editorial, page 2242

Supplemental data at Neurology.org

\section{ABSTRACT}

Objective: To compare the accuracy of Alberta Stroke Program Early Computed Tomography Score (ASPECTS) and CT perfusion to detect established infarction in acute anterior circulation stroke.

Methods: We performed an observational study in 59 acute anterior circulation ischemic stroke patients who underwent brain noncontrast CT, CT perfusion, and MRI within 100 minutes from CT imaging. ASPECTS scores were calculated by 4 blinded vascular neurologists. The accuracy of ASPECTS and CT perfusion core volume to detect an acute MRI diffusion lesion of $\geq 70 \mathrm{~mL}$ was evaluated using receiver operating characteristics analysis and optimum cutoff values were calculated using Youden J.

Results: Median ASPECTS score was 8 (interquartile range [IQR] 5-9). Median CT perfusion core volume was $22 \mathrm{~mL}$ (IQR 10.4-71.9). Median MRI diffusion lesion volume was $24.5 \mathrm{~mL}$ (IQR 1063.9). No significant difference was found between the accuracy of CT perfusion and ASPECTS (c statistic 0.95 vs $0.87, p$ value for difference $=0.17$ ). The optimum ASPECTS cutoff score to detect a diffusion-weighted imaging lesion $\geq 70 \mathrm{~mL}$ was $<7$ (sensitivity 0.74 , specificity 0.86 , Youden $\mathrm{J}=0.60$ ) and the optimum CT perfusion core volume cutoff was $\geq 50 \mathrm{~mL}$ (sensitivity 0.86 , specificity 0.97 , Youden $\mathrm{J}=0.84$ ). The $\mathrm{CT}$ perfusion core lesion covered a median of $100 \%$ (IQR 86\%-100\%) of the acute MRI lesion volume (Pearson $R=0.88 ; R^{2}=0.77$ ).

Conclusions: We found no significant difference between the accuracy of CT perfusion and ASPECTS to predict hyperacute MRI lesion volume in ischemic stroke. Neurology ${ }^{\circledR}$ 2017;88:2248-2253

\section{GLOSSARY}

ASPECTS = Alberta Stroke Program Early Computed Tomography Score; AUC $=$ area under the receiver operating characteristic curve; $\mathbf{D W I}=$ diffusion-weighted imaging; ICC = intraclass correlation coefficient; $\mathbf{I Q R}=$ interquartile range; NPV = negative predictive value; PPV = positive predictive value

Acute ischemic stroke patients with large established infarction treated with reperfusion therapy are more likely to have a poor functional outcome and reperfusion edema or haemorrhage. ${ }^{1}$ The Alberta Stroke Program Early Computed Tomography Score (ASPECTS) score is a 10-item score assessing brain parenchyma hypodensity in predefined anterior circulation regions on brain noncontrast CT as a marker of early ischemic changes. ${ }^{2}$ Use of the score was part of the imaging inclusion criteria in several large randomized clinical trials on endovascular clot retrieval in ischemic stroke. ${ }^{3-5}$ The ASPECTS score is widely used to identify acute ischemic stroke patients with established infarction who may not benefit or may be harmed by reperfusion therapy. Although the ASPECTS score correlates well with functional outcome in ischemic stroke patients evaluated for thrombolysis, correlation with functional outcome after thrombectomy is less robust, especially when a cutoff value of the score is used to exclude patients from

\footnotetext{
*These authors contributed equally to this work.

From the Acute Stroke Service (J.D., C.G.-E., F.O., M.P., C.L.), John Hunter Hospital, Newcastle, Australia; Hamad Medical Corporation (P.G.-B.), Doha, Qatar; Hunter Medical Research Institute (P.M., A.B.), Newcastle; and University of Newcastle (P.M., M.P., C.L.), Callaghan, Australia.

Go to Neurology.org for full disclosures. Funding information and disclosures deemed relevant by the authors, if any, are provided at the end of the article. The Article Processing Charge was funded by The University of Newcastle, Australia.

This is an open access article distributed under the terms of the Creative Commons Attribution-NonCommercial-NoDerivatives License 4.0 (CC BY-NC-ND), which permits downloading and sharing the work provided it is properly cited. The work cannot be changed in any way or used commercially without permission from the journal.
} 
Figure 1 Noncontrast CT, core (red) and penumbra (green) CT perfusion maps, and acute diffusion-weighted imaging (DWI) MRI in 3 different patients
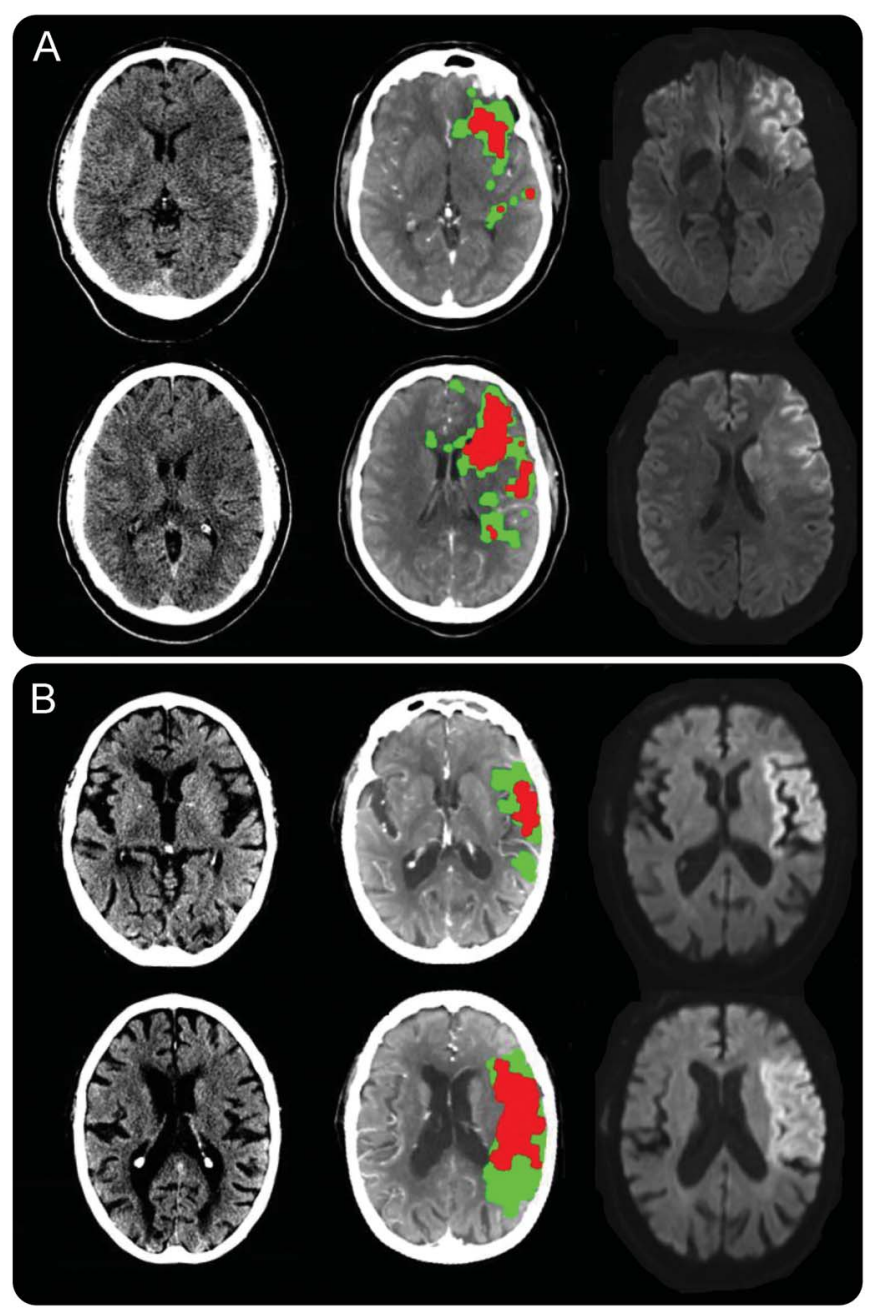

(A) Agreement among all imaging modalities (Alberta Stroke Program Early Computed Tomography Score [ASPECTS] score 5, CT perfusion core volume $58 \mathrm{~mL}$, MRI DWI volume $106 \mathrm{~mL}$ ). (B) Established large infarct with high ASPECTS score (ASPECTS score 9, CT perfusion core volume $52 \mathrm{~mL}$, MRI DWI volume $90 \mathrm{~mL}$ ).

treatment. ${ }^{2,6-8}$ Benefit of thrombectomy is preserved in patients with ASPECTS scores lower than the cutoff value proposed in the ASPECTS validation study (i.e., 8) and in patients with scores lower than the cutoff value commonly used for selection of patients for reperfusion therapy (i.e., 6 or 7). ${ }^{2,8}$

CT perfusion to evaluate ischemic core and penumbra volume of ischemic stroke has shown to correlate well with acute MRI diffusion-weighted imaging (DWI) lesion volume. ${ }^{9,10}$ Compared to acute brain MRI, CT perfusion is more readily available and rapidly acquired. ' Software processing of CT perfusion source images can generate ischemic core and penumbra maps that can accurately identify the acute infarct and tissue at risk for infarction. ${ }^{10}$ The addition of CT perfusion imaging, however, is more time-consuming compared to noncontrast CT and CT angiography imaging alone.

We therefore aimed to compare the accuracy of brain noncontrast CT ASPECTS and CT perfusion core volume to identify patients with established infarction.

METHODS Patient population. We retrospectively analyzed a convenience series of 59 confirmed acute anterior circulation ischemic stroke patients between May 2003 and December 2011 who presented within 6 hours from stroke onset and underwent acute multimodal CT as well as MRI. Each patient underwent a noncontrast CT, CT angiography, and CT perfusion as part of the standard acute stroke assessment. All patients then went on to have MRI brain within 100 minutes from CT perfusion. Thrombolytic treatment was initiated between CT and MRI in eligible patients. As this study was performed before validation of endovascular clot retrieval therapy in acute ischemic stroke, no patient received a thrombectomy.

Imaging protocol. CT imaging was performed on a 16-slice Philips (Best, the Netherlands) Mx8000 or a 64-slice Philips Brilliance. A $40 \mathrm{~mL}$ bolus of contrast agent (Ultravist 370; Bayer HealthCare, Whippany, NJ) at a rate of $6 \mathrm{~mL} / \mathrm{s}$ was used to acquire CT perfusion images at 45 time points of 1.33 seconds. Four to eight adjacent 5- to 6-mm slices covered $24-40 \mathrm{~mm}$ sections, using a 16- or 64-slice scanner, respectively. We used commercially available MIStar software (Apollo Medical Imaging Technology, Melbourne, Australia) to process CT perfusion images and generate cerebral blood volume, cerebral blood flow, mean transit time, and delay time, as well as ischemic core and penumbra maps. ${ }^{10-12}$ Core and penumbra maps are graphically represented as red and green areas, respectively, superimposed on the noncontrast CT (figure 1). The software automatically selects global arterial input function from a large intracranial artery and a venous outflow function from a large draining cerebral venous sinus. A model-free singular value decomposition is used to deconvolve the tissue enhancement curve and the arterial input function with automated delay and dispersion correction. ${ }^{13,14}$ Core infarct is defined as the brain region with a relative cerebral blood flow of less than $30 \%$ (compared to the contralateral hemisphere) within a region with a delay time of more than 3 seconds and a minimum cluster size of $5 \mathrm{~mm}$. The perfusion lesion is defined as the region with a delay time of more than 3 seconds and the penumbra as perfusion lesion after exclusion of the ischemic core. Areas of no blood flow, chronic infarction, or CSF regions are automatically masked from the perfusion maps: no blood flow pixels are removed by eliminating areas where cerebral blood flow $=0$ and a Hounsfield threshold and geometrical analysis is used to remove skull and CSF or ventricle pixels.

MRI brain was performed on a $1.5 \mathrm{~T}$ MRI (Siemens [Munich, Germany] Avanto) and included axial isotropic DWI, echoplanar spin-echo sequence, time of flight magnetic resonance angiography, and bolus-tracking perfusion-weighted imaging. ${ }^{15}$

Data collection. Prior to data collection, patients with missing imaging data were excluded $(n=5)$. ASPECTS was performed by 4 independent vascular neurologists at 2 centers. Assessors were unblinded to the affected hemisphere. CT images were assessed using nonstandard, variable soft copy, narrow window 
and level settings centered between 35-45 HU width and 35-45 HU level (aspectsinstroke.com). After collection of all imaging data, a consensus meeting was organized to solve disagreement between raters and to obtain a single ASPECTS score per patient. We used commercial MIStar software to calculate the ischemic core volume on CT perfusion, applying the abovementioned thresholds. CT perfusion imaging analysis was performed after ASPECTS rating. We used an area of interest tool for semiautomated selection of lesion outline to delineate acute MRI DWI lesions based on signal intensity (contrast). The tool automatically measured the volume of the DWI lesion by adding the highlighted area in each slice the lesion was visualized. A DWI lesion volume of at least $70 \mathrm{~mL}$ was chosen to represent a large infarct volume beyond which the benefit of IV reperfusion therapy may be limited. ${ }^{10,16,17}$ Assessment of MRI DWI lesions was performed after acute CT perfusion imaging analysis. Before perfusion postprocessing, CT perfusion source images were coregistered to the corresponding MRI DWI images. Next, the MRI DWI areas of interest were transferred to the coregistered acute CT perfusion core-penumbra maps for statistical volume analysis. Volume coverage of the acute MRI DWI lesion by the CT perfusion core lesion was then calculated.

Statistical analysis. All statistical analyses were performed with SPSS version 20 (IBM Corp., Armonk, NY). The area under the receiver operating characteristic curve (AUC) was calculated to estimate the accuracy of noncontrast CT ASPECTS and CT perfusion core volume to predict a large acute MRI DWI lesion volume $(>70 \mathrm{~mL})$ and the method of Delong et al. was applied to compare the AUC between ASPECTS and CT perfusion. ${ }^{18}$ Sensitivity, specificity, positive predictive value (PPV), negative predictive value (NPV), and correct classification rate were then calculated for different ASPECTS cutoff scores and CT perfusion core volume cutoffs to predict a DWI lesion of at least $70 \mathrm{~mL}$ using standard $2 \times 2$ contingency table methodology. Next, the Youden index was used to determine the optimum ASPECTS cutoff score and CT perfusion core volume. Intraclass correlation coefficient (ICC) was used to estimate interrater agreement for ASPECTS scoring (2-way mixed effects model with measures of absolute agreement). AUC was used to determine accuracy for ASPECTS, CT perfusion core volume, and MRI DWI lesion volume to predict poor functional outcome at 90 days after the stroke, defined as a modified Rankin Scale score of 3-6.

The correlation between CT perfusion core volume and MRI DWI lesion volume was measured by calculating Pearson correlation coefficient (Pearson $R$ ) and the coefficient of determination $\left(R^{2}\right)$. ICC was calculated as a measure for agreement between CT perfusion core volume and DWI lesion volume. A scatterplot and Bland-Altman plot was used to further examine the correlation between CT perfusion and MRI DWI lesion volume.

A Wilcoxon rank sum test was used to assess statistical differences between onset and imaging time in patients with high vs low ASPECTS scores.

Standard protocol approvals, registrations, and patient consents. The study was approved by the Hunter New England Human Research Ethics Committee and all patients gave informed consent.

RESULTS Patient characteristics. The median patient age was 76 years (interquartile range [IQR] 68-84). Forty-nine percent of the population was male. Median NIH Stroke Scale score at admission was 15 (IQR 12-17). Median onset to admission time was 157 minutes (IQR 113-166). Median time from symptom onset to start of imaging was 200 minutes (IQR 177-249). The acute MRI brain was performed at a median of 60 minutes after CT imaging (IQR 34-98 minutes). Time from onset to start of imaging did not differ between high (i.e., 7-10) and low (i.e., 0-6) ASPECTS score subgroups (193 minutes [IQR 168-221] vs 228 minutes [IQR 187-276]; $p=$ $0.08)$.

Twenty-nine patients (49\%) were thrombolyzed. The other patients were either outside of the thrombolysis time window or were excluded from thrombolysis because of large established infarction on CT imaging or comorbidity.

Imaging characteristics. ASPECTS scores ranged from 1 to 10 . Median consensus ASPECTS score was 8 (IQR 5-9). Sixty-three percent of patients had an ASPECTS score of 7 or higher. Eighty-eight percent of patients had an ASPECTS score of 4 or higher (table e-1 and figure e-1 at Neurology.org). ASPECTS interrater agreement was good (ICC 0.71 ). More details about the interrater reliability can be found in the supplemental data.

CT perfusion ischemic core volumes ranged from 0 to $188 \mathrm{~mL}$. Median lesion volume was $22 \mathrm{~mL}$ (IQR 10.4-71.9). Twenty patients (34\%) had a CT perfusion core volume of at least $50 \mathrm{~mL}$ and 16 patients (27\%) had a core volume of $70 \mathrm{~mL}$ or more (table e-2). Median acute MRI DWI lesion volume was $24.5 \mathrm{~mL}$ (IQR 10-63.9 mL). DWI lesion volume ranged from 1.3 to $215 \mathrm{~mL}$.

Forty-nine patients (83\%) had a documented large vessel occlusion. In 27 patients $(55 \%$ of large vessel occlusions), the M1 segment of the middle cerebral artery was occluded, and in 15 patients (31\% of large vessel occlusions), the carotid was occluded or a carotid-middle cerebral artery tandem lesion was present. At the time of MRI, complete vessel recanalization had occurred in 10 patients (20\%). Twenty-one patients (43\%) showed a persistent occlusion. The other 18 patients $(41 \%)$ had partial recanalization.

Correlation of noncontrast CT ASPECTS score with acute MRI DWI lesion volume. Conventional ASPECTS had a good overall accuracy to predict an acute MRI DWI lesion volume of at least $70 \mathrm{~mL}$ (AUC 0.87 [95\% CI 0.78-0.96]; figure 2, table e-1). The ASPECTS cutoff value of $<7$ (i.e., $0-6$ vs 7-10) had an optimum Youden index of 0.60. At this cutoff value, sensitivity to detect an acute DWI lesion $\geq 70 \mathrm{~mL}$ was 0.74 , specificity was 0.86 , PPV was 0.77 , and NPV was 0.84 (figure 2, table e-1). Eighty-one percent of patients were correctly classified as either small or large volume lesion. Using a cutoff score of $<7,5$ patients (8.5\%) with small DWI lesions would be excluded from 

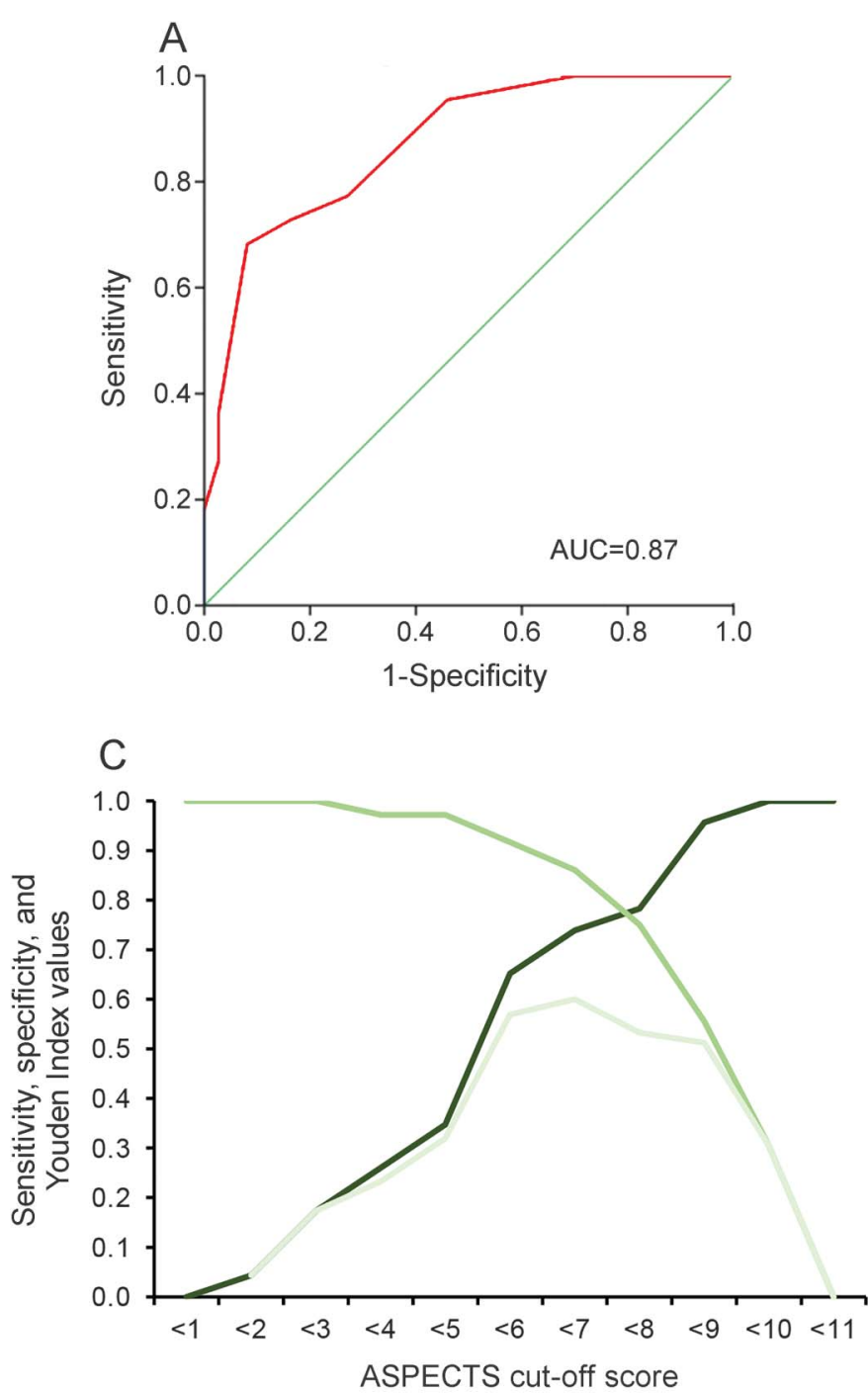
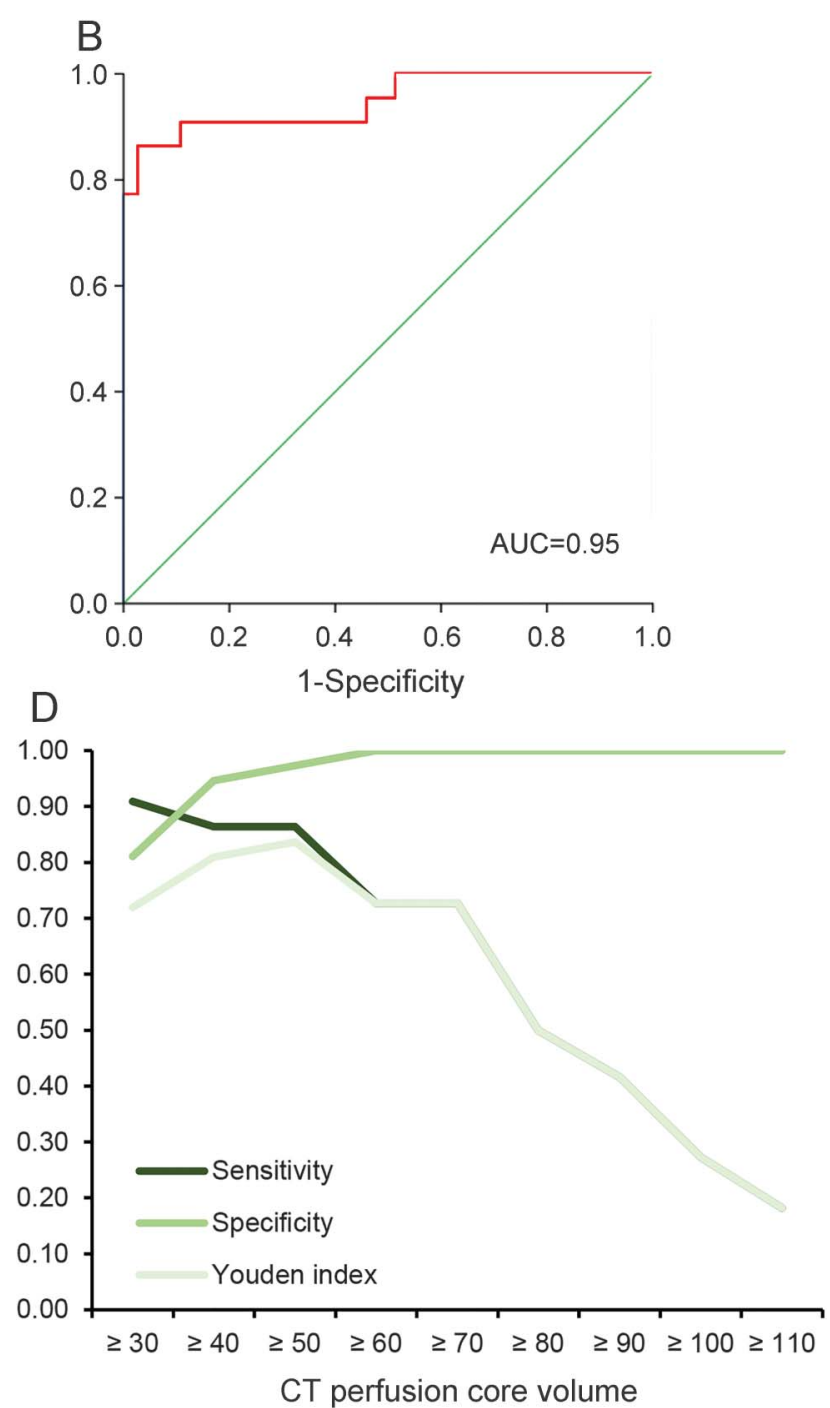

Receiver operating characteristic curves for Alberta Stroke Program Early Computed Tomography Score (ASPECTS) (A) and CT perfusion (B). State variable: MRI diffusion lesion smaller or larger than $70 \mathrm{~mL}$. Sensitivity, specificity, and Youden index for different ASPECTS cutoff values (C) and CT perfusion core volume cutoffs (D). AUC = area under the curve.

reperfusion therapy and 6 patients $(10 \%)$ with large DWI lesions would undergo reperfusion treatment. The other ASPECTS cutoff score used in several thrombectomy trials (i.e., $<6$ ) had a sensitivity of 0.65 and a specificity of 0.92 (figure 2, table e-1).

Correlation of CT perfusion volume with acute MRI DWI lesion volume. CT perfusion core volume had excellent accuracy to predict an acute DWI lesion volume of $\geq 70 \mathrm{~mL}$ (AUC 0.95 [95\% CI 0.89-1.00]; figure 2, table e-2). The cutoff CT perfusion core volume of at least $50 \mathrm{~mL}$ most accurately matched a DWI lesion of $\geq 70 \mathrm{~mL}$ (sensitivity 0.86 , specificity 0.97, PPV 0.95, NPV 0.92, Youden index 0.84; figure 2, table e-2). Using this volume cutoff, 1 patient (2\%) would erroneously be refused therapy and 3 patients $(5 \%)$ with large DWI lesions would be missed.
There was no significant difference between the accuracy of CT perfusion and ASPECTS to predict an acute DWI lesion of at least $70 \mathrm{~mL}(p=0.17)$.

The CT perfusion core volume covered on average 90.3\% of the MRI DWI lesion (range 32\%-100\%; median 100\%; IQR 86\%-100\%; Pearson $R=0.88$; $R^{2}=0.77$; figure e-2). ICC between CT perfusion core volume and DWI lesion volume was 0.77 (95\% CI 0.22-0.90). Larger DWI lesions in particular were significantly underestimated by CT perfusion (bias $-39 \mathrm{~mL}$; median volume difference $-30 \mathrm{~mL}$; IQR -4 to $-57 \mathrm{~mL} ; p<0.001$; Bland-Altman plot, see figure e-3).

Correlation of ASPECTS, CT perfusion, and MRI with functional outcome. MRI DWI lesion volume most accurately predicted a poor clinical outcome (AUC 0.95 [95\% CI 0.90-1.00]). The accuracy of CT 
perfusion core volume and ASPECTS was comparable (AUC 0.79 [95\% CI 0.67-0.90] vs AUC 0.75 [95\% CI 0.62-0.87]).

DISCUSSION In this study, we compared the accuracy of ASPECTS with automated CT perfusion core volume estimation to identify patients with established large infarcts on hyperacute MRI, defined as an MRI DWI lesion volume of at least $70 \mathrm{~mL}$. We found no significant difference between the accuracy of ASPECTS and CT perfusion to identify patients with a large DWI lesion (AUC 0.87 vs 0.95 , respectively, $p=0.17$ ).

The optimum cutoff values for ASPECTS and CT perfusion core volume, however, did result in a higher number of patients incorrectly classified as large or small established infarcts with use of ASPECTS. The optimum ASPECTS cutoff score of $<7$ resulted in a higher number of false-positive cases and a lower number of correctly classified patients when compared to CT perfusion $(8.5 \%$ vs $2 \%$ and $81 \%$ vs $93 \%$, respectively). The lower specificity of ASPECTS to identify patients with large established brain infarction may in part explain the findings of the retrospective analysis of the unselected endovascular clot retrieval trial Multicenter Randomized Clinical Trial of Endovascular Treatment for Acute Ischemic Stroke in the Netherlands (MR CLEAN), in which thrombectomy increased the chance of independence by $19 \%$ in patients with an ASPECTS score of $5-7 .{ }^{8}$ Conversely, our data indicate that many patients with a normal or near normal brain noncontrast CT (i.e., ASPECTS 8-10) might already have a large area of established infarction. Compared to the optimum CT perfusion cutoff value of $\geq 50$ $\mathrm{mL}$, use of ASPECTS doubled the number of patients erroneously categorized as small volume established lesions. These findings could not be explained by the relative insensitivity of ASPECTS in the very early phase of ischemic stroke.

Although the overall agreement on the ASPECTS score was good, absolute agreement between raters was low and we found significant heterogeneity between individual raters (see supplemental data). These findings are consistent with a recent large meta-analysis and may further complicate the use of the ASPECTS score. ${ }^{19}$ Where interrater variability limits the use of ASPECTS scoring for selection of patients for reperfusion therapy, CT perfusion software automatically creates core and penumbra maps and calculates core and penumbra volumes that do not need further interpretation.

The accuracy of CT perfusion core volume to predict a large MRI DWI lesion was excellent, and the optimum cutoff volume of $\geq 50 \mathrm{~mL}$ was highly specific and resulted in $93 \%$ of patients correctly classified. We did, however, see a tendency to underestimate the volume of large DWI lesions, resulting in a lower optimum volume threshold. The stronger correlation between the CT perfusion and DWI lesion volume may in part explain the enhanced absolute and relative benefit seen in the randomized trials on endovascular clot retrieval where CT perfusion was used in patient selection as compared to CT angiography alone or CT angiography and ASPECTS: CT perfusion patient selection yielded the highest number of patients without disability 3 months postintervention $(71 \%$ vs $32.6 \%-$ $60 \%) .^{3-5,16,20,21}$ In our population, accuracy to predict clinical outcome was only slightly higher for CT perfusion when compared to ASPECTS. As opposed to the abovementioned trials on endovascular treatment, a large proportion of patients in this study did not achieve reperfusion.

Our study has some limitations and caveats. First, the study sample size is low, which may render us underpowered to find a significant difference between CT perfusion and ASPECTS. Furthermore, the limited number of patients with low ASPECTS scores (15\% of patients had an ASPECTS score lower than 5) does not allow us to comment on the accuracy of ASPECTS scores $0-4$ to detect very large volumes of established infarct. Second, ASPECTS training differed significantly between individual raters, which is reflected in the interrater reliability results. However, significant heterogeneity in ASPECTS experience is to be expected in daily practice and has been demonstrated to further limit the usefulness of the ASPECTS score. ${ }^{18}$ Third, we were not able to evaluate the accuracy of multiphase CT angiography. Finally, imaging techniques have evolved during the study period, which may affect the generalizability of our findings. Subanalysis of our results, although limited by the small sample size, does not show a significant difference in patients imaged with a third- vs fourth-generation helical CT scanner (figure e-4).

Although the accuracy of ASPECTS and CT perfusion to evaluate a large area of established infarction was similar, the lower false-positive and false-negative rate seen with CT perfusion makes it a more suitable tool for patient selection for IV therapy. Furthermore, CT perfusion has the additional benefit of providing information about the volume and location of the tissue at risk. Although there currently is insufficient evidence to exclude a subgroup of acute ischemic stroke patients from reperfusion treatment, our findings suggest CT perfusion may be more reliable and accurate than ASPECTS to further evaluate this query.

\section{AUTHOR CONTRIBUTIONS}

Jelle Demeestere: study concept and design, data acquisition, statistical analysis, interpretation of data. Carlos Garcia-Esperon: study concept and design, data acquisition, interpretation of data. Pablo 
Garcia-Bermejo: data acquisition, critical revision of manuscript for intellectual content. Fouke Ombelet: data acquisition. Pactrick McElduff: statistical analysis. Andrew Bivard: study concept and design, interpretation of data, critical revision of manuscript for intellectual content. Mark Parsons: data acquisition, interpretation of data, critical revision of manuscript for intellectual content. Christopher Levi: study concept and design, interpretation of data, critical revision of manuscript for intellectual content.

\section{STUDY FUNDING}

No targeted funding reported.

\section{DISCLOSURE}

The authors report no disclosures relevant to the manuscript. Go to Neurology.org for full disclosures.

Received August 11, 2016. Accepted in final form March 16, 2017

\section{REFERENCES}

1. Olivot JM, Mosimann PJ, Labreuche J, et al. Impact of diffusion-weighted imaging lesion volume on the success of endovascular reperfusion therapy. Stroke 2013;44:2205-2211.

2. Barber PA, Demchuk AM, Zhang J, Buchan AM. Validity and reliability of a quantitative computed tomography score in predicting outcome of hyperacute stroke before thrombolytic therapy: ASPECTS Study Group: Alberta Stroke Programme Early CT Score. Lancet 2000;355:1670-1674.

3. Goyal M, Demchuk AM, Menon BK, et al. Randomized assessment of rapid endovascular treatment of ischemic stroke. N Engl J Med 2015;372:1019-1030.

4. Saver JL, Goyal M, Bonafe A, et al. Stent-retriever thrombectomy after intravenous t-PA vs. t-PA alone in stroke. N Engl J Med 2015;372:2285-2295.

5. Jovin TG, Chamorro A, Cobo E, et al. Thrombectomy within 8 hours after symptom onset in ischemic stroke. N Engl J Med 2015;372:2296-2306.

6. Hill MD, Rowley HA, Adler F, et al. Selection of acute ischemic stroke patients for intra-arterial thrombolysis with pro-urokinase by using ASPECTS. Stroke 2003;34: 1925-1931.

7. Goyal M, Menon BK, van Zwam WH, et al. Endovascular thrombectomy after large-vessel ischaemic stroke: a metaanalysis of individual patient data from five randomised trials. Lancet 2016;387:1723-1731.

8. Yoo AJ, Berkhemer OA, Fransen PS, et al. Effect of baseline Alberta Stroke Program Early CT Score on safety and efficacy of intra-arterial treatment: a subgroup analysis of a randomised phase 3 trial (MR CLEAN). Lancet Neurol 2016;15:685-694.

9. Parsons MW. Perfusion CT: is it clinically useful? Int J Stroke 2008;3:41-50.

10. Bivard A, Spratt N, Levi C, Parsons M. Perfusion computer tomography: imaging and clinical validation in acute ischaemic stroke. Brain 2011;134:3408-3416.

11. Parsons MW, Pepper EM, Chan V, et al. Perfusion computed tomography: prediction of final infarct extent and stroke outcome. Ann Neurol 2005;58:672-679.

12. Parsons MW, Pepper EM, Bateman GA, Wang Y, Levi CR. Identification of the penumbra and infarct core on hyperacute noncontrast and perfusion CT. Neurology 2007;68: 730-736.

13. Yang Q. Method and system of obtaining improved data in perfusion measurements. US patent no. 8,855,985. 2014.

14. Yang Q. Method and system for mapping tissue status of acute stroke. US patent no. 8,942,451. January 27, 2015.

15. Parsons MW, Miteff F, Bateman GA, et al. Acute ischemic stroke: imaging-guided tenecteplase treatment in an extended time window. Neurology 2009;72:915-921.

16. Campbell BC, Mitchell PJ, Kleinig TJ, et al. Endovascular therapy for ischemic stroke with perfusion-imaging selection. N Engl J Med 2015;372:1009-1018.

17. Lansberg MG, Straka M, Kemps S, et al. Magnetic resonance imaging profile and response to endovascular reperfusion: results of the DEFUSE 2 prospective cohort study. Lancet Neurol 2012;11:860-867.

18. DeLong ER, DeLong DM, Clarke-Pearson DL. Comparing the areas under two or more correlated receiver operating characteristic curves: a nonparametric approach. Biometrics 1988;44:837-845.

19. Farzin B, Fahed R, Guilbert F, et al. Early CT changes in patients admitted for thrombectomy: intrarater and interrater agreement. Neurology 2016;87:249-256.

20. Berkhemer OA, Fransen PS, Beumer D, et al. A randomized trial of intraarterial treatment for acute ischemic stroke. N Engl J Med 2015;372:11-20.

21. Bracard S, Ducrocq X, Mas JL, et al. Mechanical thrombectomy after intravenous alteplase versus alteplase alone after stroke (THRACE): a randomised controlled trial. Lancet Neurol 2016:1138-1147.

\section{Subspecialty Alerts by E-mail!}

Customize your online journal experience by signing up for e-mail alerts related to your subspecialty or area of interest. Access this free service by visiting Neurology.org/site/subscriptions/etoc.xhtml or click on the "E-mail Alerts" link on the home page. An extensive list of subspecialties, methods, and study design choices will be available for you to choose from-allowing you priority alerts to cutting-edge research in your field! 


\section{Neurology}

Evaluation of hyperacute infarct volume using ASPECTS and brain CT perfusion core volume

Jelle Demeestere, Carlos Garcia-Esperon, Pablo Garcia-Bermejo, et al.

Neurology 2017;88;2248-2253 Published Online before print May 17, 2017

DOI 10.1212/WNL.0000000000004028

This information is current as of May 17, 2017

Neurology ${ }^{\circledR}$ is the official journal of the American Academy of Neurology. Published continuously since 1951, it is now a weekly with 48 issues per year. Copyright Copyright (C) 2017 The Author(s). Published by Wolters Kluwer Health, Inc. on behalf of the American Academy of Neurology. All rights reserved. Print ISSN: 0028-3878. Online ISSN: 1526-632X.

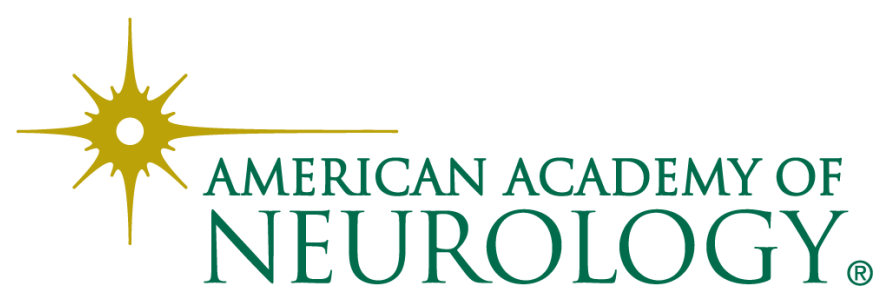




\section{Updated Information \& Services}

\section{Supplementary Material}

\section{References}

Citations

Subspecialty Collections

Permissions \& Licensing

\section{Reprints}

including high resolution figures, can be found at: http://n.neurology.org/content/88/24/2248.full

Supplementary material can be found at: http://n.neurology.org/content/suppl/2017/05/17/WNL.0000000000004 028.DC1

http://n.neurology.org/content/suppl/2017/05/17/WNL.0000000000004 028.DC2

This article cites 18 articles, 4 of which you can access for free at: http://n.neurology.org/content/88/24/2248.full\#ref-list-1

This article has been cited by 8 HighWire-hosted articles: http://n.neurology.org/content/88/24/2248.full\#\#otherarticles

This article, along with others on similar topics, appears in the following collection(s):

\section{All Cerebrovascular disease/Stroke}

http://n.neurology.org/cgi/collection/all_cerebrovascular_disease_strok e

\section{CT}

http://n.neurology.org/cgi/collection/ct

\section{MRI}

http://n.neurology.org/cgi/collection/mri

Information about reproducing this article in parts (figures,tables) or in its entirety can be found online at:

http://www.neurology.org/about/about_the_journal\#permissions

Information about ordering reprints can be found online:

http://n.neurology.org/subscribers/advertise

Neurology ${ }^{\circledR}$ is the official journal of the American Academy of Neurology. Published continuously since 1951, it is now a weekly with 48 issues per year. Copyright Copyright ( 2017 The Author(s). Published by Wolters Kluwer Health, Inc. on behalf of the American Academy of Neurology. All rights reserved. Print ISSN: 0028-3878. Online ISSN: 1526-632X.

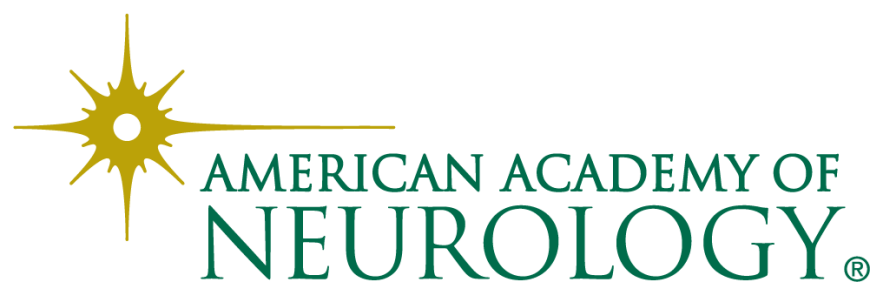

